\title{
Formation and development of technotopia as a concept of the figurative and stylistic direction of innovative architectural activity
}

\author{
Alexander Pleshivtsev ${ }^{1, *}$ and Tatiana Pakunova ${ }^{1}$ \\ ${ }^{1}$ State University of land management, 105064, 15, Kazakova str., Moscow, Russia
}

\begin{abstract}
Purpose: to analyze the modern display of utopian ideas in architectural activity for the development of innovative directions of organization and forming of the object environment, to identify and define the features of technotopia as a figurative and stylistic direction that combines idealistic and pragmatic principles in architectural creativity. Methods and materials: empirical and theoretical methods of analogy and abstraction focused on analyzing the properties, possibilities and conditions that determine the features of utopian ideas displayed in architectural creativity. A method of generalizing the experience of theoretical knowledge and development in the implementation of innovative technological solutions for architectural objects. Results: A two-level structure of signs of utopia in architectural creativity was developed. An algorithm for transforming ideas about an ideal world is proposed, taking into account the possibilities of practical implementation of technological priorities in architectural activity. The properties of technotopia as a figurative and stylistic direction characterizing the features of the practical implementation of technological priorities of architectural activity have been confirmed. Conclusions: The study of the nature of utopias is one of the key topics and opportunities for the development of promising figurative and stylistic directions in architectural creativity. The fundamental idealistic (utopian) principle of architectural creativity is capable of evolution through integration with the results and possibilities of technological progress of various fields of knowledge. Technological priorities in the organization of architectural space make it possible to significantly expand the possibilities of traditional compositional techniques in solving applied and practical problems of architectural activity.
\end{abstract}

\section{Idealistic and pragmatic principles in modern architectural activity}

Each architectural concept (image, project) contains an idealistic (utopian) and pragmatic principle in an attempt to organize and display the subject-spatial environment. The utopian beginning of architectural activity reflects a certain "super idea", "ideal

\footnotetext{
*Corresponding author: perspektiva-aa@mail.ru
} 
image", "metaphysics of architecture". The term "utopia" translated from Greek (ov "not"

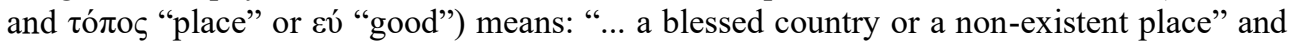
denotes a non-existent ideal, which, nevertheless, can be approached $[1,2,3]$.

Nowadays, due to the lack of a precise definition of a single set of features and criteria, the term "utopia" is blurred and is used in relation to almost all large-scale projects (activities). Utopia, as one of the possible types of creative activity, is characterized by a set of stable features and display features.

In a commonly used sense, the concept (term) "utopia" has become widespread for the semantic identification of conditions and/or a lack of prerequisites for the implementation of large-scale and difficult-to-implement projects or forecasts in various areas of creative or practical activity. Moreover, it is the "scale" characteristic that is taken as a negatively accentuated property of projects in order to be called utopian projects or events identified with creative processes and transformations of material and non-material space.

This approach comes into conflict with the creative and fundamentally realizable logic and practical results of architectural creativity. Architecture, being a creative, positive and programmatic type of theoretical and pragmatic activity, is inextricably linked with the development of utopian thought and creativity, starting from the historical eras of Antiquity and the Renaissance $[1,4,5,6]$.

The genesis of the development of utopian ideas includes successive stages of development: from the search for a romantic image to the formation of their purely pragmatic ideas. The balance saturation and proportional distribution of the utopian and pragmatic principles are different for each architectural image, but they are necessarily present in each project (subject of architectural creativity). The pragmatic beginning is the "physical" compliance with technological, functional, structural, operational criteria and conditions.

Progress in the development of resources and opportunities for creative activities, primarily intellectual, technical and technological ones, prompts intentions in the development and implementation of the architectural ideal here and now. For this reason, the creative genre of utopia has transformed from abstract, theoretical reasoning into the subject of searches for applied recipes and solutions in architectural activity.

The utopian idea in architecture is a representation of the ideal organization of the surrounding subject-spatial environment, and the utopia contains the figurative, fundamental basis of architectural creativity. Architectural utopia can be considered as a way of reflecting the principles of idealized consciousness in the formation of an architectural work, implying the presence of a "creative composition of an ideal image", which is proposed as a subjective form of representation of the desired reality $[7,8,9]$.

The combination of methods of abstract philosophy and practical creation reflects the main essence of architectural activity, and, in fact, architecture is one of the most significant tools for finding and organizing ideal space and harmony. Understanding the peculiarities of the processes of formation and transformation of utopian ideas, the cyclical and paradoxical nature of these processes, understanding the reasons for their appearance and their possible consequences will allow a deeper understanding of the essence of the creative process, the reasons and patterns of manifestation of architectural thought, as well as predict the main development trends and results of displaying architectural creativity [7, $10]$.

To assess architectural projects and determine common structural features and relationships, a two-level structure of utopia features can be adopted:

- main signs:

○ novelty;

- radicalism;

○ totality (due to its logical nature); 
- timelessness (lack of spatial development, changes in time);

○ autarky (self-sufficiency and self-dependence, spatial isolation);

$\circ$ determinism or limitation of the development process;

- hierarchical subordination and regulations for social processes and phenomena.

- indirect (secondary) signs:

- presence of a dominant style;

○ the use of an excessive, hyperbolized scale ("gigantism") as the main means of displaying the features of the work;

$\circ$ monotony and like-mindedness;

- lack of internal conflicts.

Topical issues and modern trends, containing the characteristic features of architectural utopias, are much more complex phenomena than their representations for past historical eras. The social and scientific role of an architectural utopia is controversial and is largely determined by the conjuncture of a specific situation.

The peculiarity of the current state and trends of architectural utopia lies, first of all, in the presence of the necessary conditions for conducting analytical studies of the genesis of the forms and content of the type of consciousness under consideration, in accordance with the characteristic features of the corresponding era, and allows for the possibility of making predictive assessments of promising directions for the development of style trends.

\section{The concept and possibilities of technological formation of the subject-spatial environment of the architectural space}

From the total mass of modern utopian projects, one of the most noticeable directions stands out, which is evolutionarily formed through the integration of utopian representations of the ideal world of previous historical eras and the technological capabilities of the present time. The technotopia direction is focused on the implementation of technological priorities (including those that are not currently available) in existing architectural projects for new and existing objects [11,12].

One of the fundamental points in the formation of the methodological base of technotopia is the fact of continuity: it not only does not deny, but rather complements the theoretical concepts of architectural utopia, including their most important achievements, expands the subject of analysis, allows a new look at the processes of evolution and transformation of architectural space and corresponding architectural images. The signs of modern technotopia in a categorical (and more often grotesque, intolerant to the experience of the history of the development of architectural science) form reflect the features and possibilities of implementing unconventional compositional solutions supported by the appropriate technological performance $[13,14,15]$.

Figure 1 shows examples of compositional and technological solutions that reflect the modern representation of the interaction of the form and the functional content of architectural images through the methods and means of technotopia. 

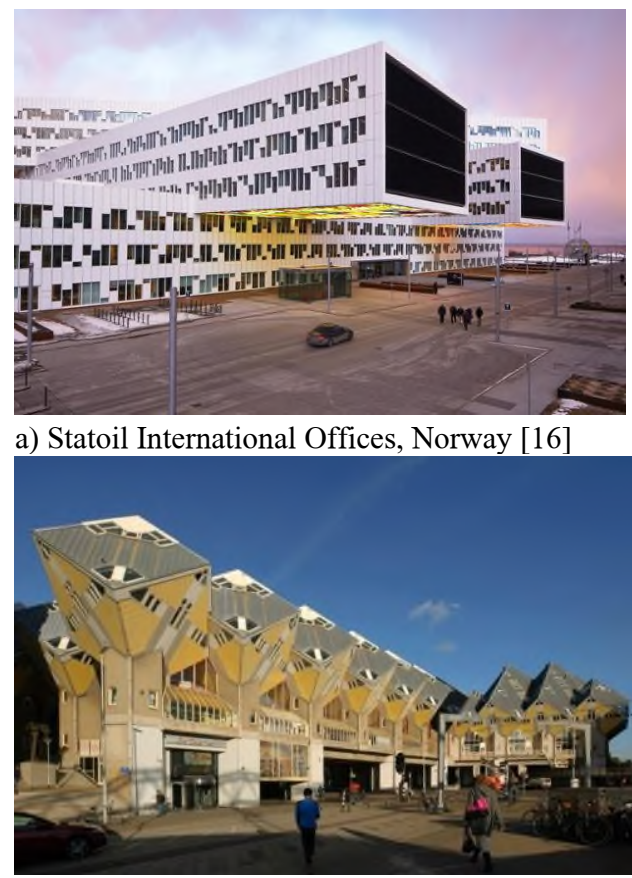

c) Kubuswoningen, Nederland [18]

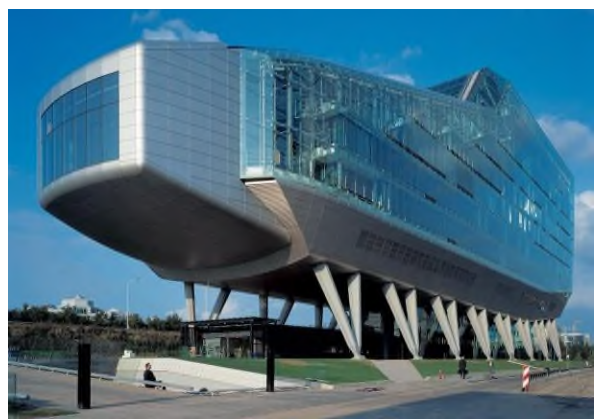

b) ING House, Nederland [17]

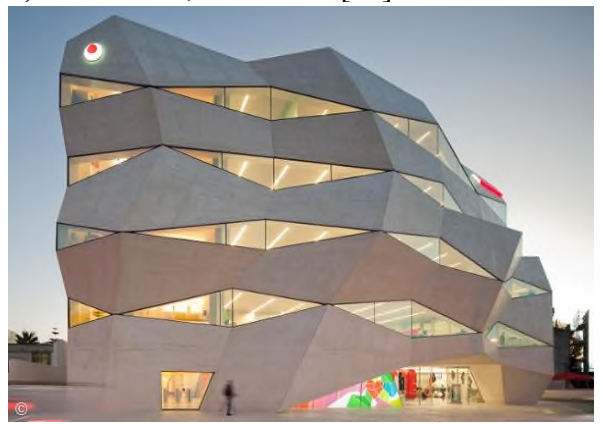

d) Vodafone Headquarters, Portugal [19]

Fig. 1. Features of shaping expressed by means and techniques of technotopia.

For the considered architectural images, a creative (in a certain sense, utopian) idea allows finding a correct, rational and aesthetic solution that will reflect the set of functional, technological and design requirements necessary to harmonize interaction with the environment. The field of architectural creativity will remain a field of search for an ideal idea of the surrounding space and its main tool for its formation.

The formation of modern samples of the figurative and stylistic direction of technotopia should be considered as alternative methods of geometric and tectonic proportionality of traditional forms, accompanied by the evolution of known parameters and revolutionary organization of new properties of materials, tectonic features of innovative structural systems, technological methods of shaping architectural images [5,15,20].

Dialogue with architectural images formed according to the properties and features of traditional tectonics allows the transition to new possibilities of display (in fact, "neotectonics" as a conductor of a new concept of displaying imagery) through the consistent elimination of the problems of the technological component of the utopian beginning of the compositional solution Neotectonics is considered in the context of cultural opposition and the way of conveying the peculiarities of experimental shaping through the expression of technological possibilities and the specifics of presenting a meaningful design of an architectural image [11,21,22,23].

It is the innovative methods of shaping and construction production technologies that remain the only and practical opportunity to form, restore or increase the parameters of the functional state of architectural objects, especially for special climatic and town-planning conditions or when forming unique or technologically complex architectural systems.

The synergy of utopian and pragmatic principles for the aesthetic and rational solution of the tasks of architectural creativity is becoming a characteristic feature of the implementation of innovative technologies carried out within the framework of the stylistic direction of technotopia. 
The evolutionary development of architectural science is increasingly focused on the practical implementation of the strategy of "collision and interpretation of differences", using the novelty and diversity of technological possibilities. Technological adaptation of the achievements of various fields of knowledge in architectural creativity allows effectively solving problems associated with increasing durability and safety, and also expands the possibilities of compositional, constructive and functional transformation of architectural space.

\section{Results}

The analysis of the fundamental components (utopian and pragmatic principles) of architectural creativity is carried out. The structure of signs of an architectural utopia has been developed. The significance and algorithm of interaction of the utopian and pragmatic principles for the evolutionary development of architectural activity are revealed. The mechanism of implementation of the possibilities of the pragmatic principle, realized in the format of the figurative and stylistic direction of technotopia, into architectural creativity is considered. The possibility of expanding the traditional areas of application and methods of architectural creativity in adapting technological advances from various fields of knowledge is shown.

\section{Discussion}

In the general composition of modern concepts and the latest projects, it is rather difficult to single out the most significant results of architectural activity due to the lack of the necessary time distance. In this regard, it is permissible to analyze promising research objects as certain results that evolved from previous searches for utopia and technological methods of its practical implementation.

The utopian assessment of objects and phenomena continues to be an internal objective property or measurement of human consciousness. Therefore, the main direction of development should be considered the formation of conditions for versatile harmonious interaction with utopia instead of living according to utopia.

\section{Conclusion}

Architectural activity for the formation, maintenance and transformation of the content of the surrounding subject space is presented as a complex synthesis of artistic (utopian principle) and technological (pragmatic principle) processes, the result of which reflects a special, synthesized and integrated approach to solving situational and promising tasks aimed at ensuring conditions of functional efficiency, safety and comfort of the architectural environment.

The technological component (production effectiveness) of the formation of an architectural image is becoming an increasingly significant structural element of modern architectural and construction culture, evolution and harmonization of architectural knowledge.

\section{References}

1. A.V. Ikonnikov, Architecture of the 20th century. Utopias and reality. Volume II (Progress-Tradition, M., 2002) 
2. T.A. Pchelintseva, Functions of utopia. Patterns of development of modern science: Collection of articles (Tomsk, 1981)

3. O.A. Chepelik, Art magazine 51/52, 67-69 (2003)

4. A.A. Musatov, The architecture of ancient Greece and ancient Rome (Architecture, M., 2006)

5. E.E. Biryukova, Aesthetics of the form and content of the architectural space: dissertation for the degree of Ph.D. in Philosophy: 09.00.04 (Vladimir, 2003)

6. R. Klanten, L. Feireiss, Utopia Forever: Visions of Architecture and Urbanism (Die Gestalten Verlag, Berlin, 2011)

7. B. Goodwin, The Philosophy of Utopia (Routledge, London, 2001)

8. N. Coleman, Utopias and Architecture (Routledge, London, 2005)

9. R. Fishman, Urban Utopias in the Twentieth Century (MIT-Press, New York, 1982)

10. A.I. Khomyakov, Academia. Architecture and Creativity 3, 69-75 (2017)

11. C. Abel, Architecture, Technology and Process (Architectural Press, London, 2004)

12. F.D. Scott, Architecture or Techno-utopia: Politics after Modernism (The MIT Press, New York, 2010)

13. R. Klanten, The Tale of Tomorrow. Utopian Architecture in the Modernist Realm (Die Gestalten Verlag, Berlin, 2016)

14. P.S. Kapustin, Development of ideas about the design object in the processes of architectural thinking: dissertation for the degree of Ph.D. in Architecture: 18.00.01 (Voronezh, 1999)

15. I.A. Dobritsyna, From postmodernism to nonlinear architecture: Architecture in the context of modern philosophy and science: dissertation for the degree of Doctor of Architecture: 18.00.01 (M., 2007)

16. Statoil Regional and International Offices, https://www.archdaily.com/359599/statoilregional-and-international-offices-a-lab

17. ING House/MVSA Architects, https://www.archdaily.com/568127/ing-house-mvsaarchitects

18. AD Classics: Kubuswoningen/Piet Blom, https://www.archdaily.com/482339/adclassics-kubuswoningen-piet-blom

19. Vodafone Headquarters/Barbosa \& Guimarães, https://www.archdaily.com/54336/vodafone-headquarters-barbosa-guimaraes

20. Yu.I. Likhansky, Metaphors of the techno world in the architecture of the XX-th century (FESTU Publishing House, Vladivostok, 1999)

21. E.A. Lapshina, A.Yu. Likhansky, Vestnik of the FEFU Engineering School 2(27), 7990 (2016)

22. E. Anoshkina, E. Markovskaya, A. Mottaeva, As. Mottaeva, E3S Web of Conferences 210, 13022 (2020) https://doi.org/10.1051/e3sconf/202021013022

23. E.Yu. Shumilova, A.V. Tantsura, Collection of scientific reports of the 21 st scientific and practical conference (North-Caucasian Branch of the Belgorod State Technological University named after V.G. Shukhov, Mineralnye Vody, 2015)

24. E. Ganebnykh, O. Lezhnina, J. Zhukova, V. Kashintseva, E3S Web of Conferences 210, $10008(2020)$

25. A. Mottaeva, A. Zheltenkov, E3S Web of Conferences 33, 01038 (2018) doi: $10.1051 / \mathrm{e} 3$ sconf $/ 20183301038$ 